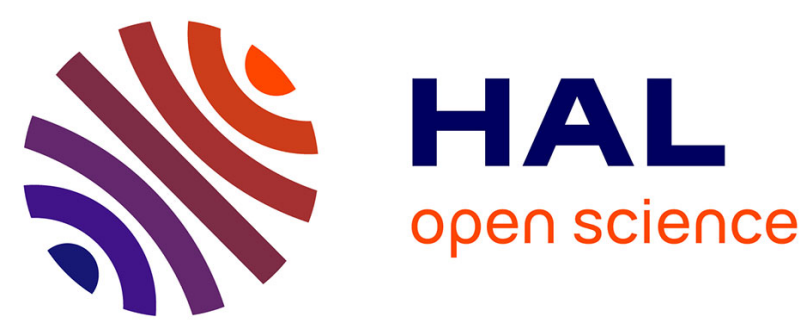

\title{
Microstructure of yttria doped ceria as a function of oxalate co-precipitation synthesis conditions
}

\author{
L. Brissonneau, A. Mathieu, B. Tormos
}

\section{To cite this version:}

L. Brissonneau, A. Mathieu, B. Tormos. Microstructure of yttria doped ceria as a function of oxalate co-precipitation synthesis conditions. Materials Science and Technology 2015, Oct 2015, Colombus, United States. 10.1007/s40553-016-0087-8 . cea-02509746

\section{HAL Id: cea-02509746 https://hal-cea.archives-ouvertes.fr/cea-02509746}

Submitted on 17 Mar 2020

HAL is a multi-disciplinary open access archive for the deposit and dissemination of scientific research documents, whether they are published or not. The documents may come from teaching and research institutions in France or abroad, or from public or private research centers.
L'archive ouverte pluridisciplinaire HAL, est destinée au dépôt et à la diffusion de documents scientifiques de niveau recherche, publiés ou non, émanant des établissements d'enseignement et de recherche français ou étrangers, des laboratoires publics ou privés. 


\title{
Microstructure of yttria doped ceria as a function of oxalate co- precipitation synthesis conditions
}

\author{
Brissonneau Laurent $^{\mathrm{a}}$, Mathieu Aurore ${ }^{\mathrm{a}}$, Tormos Brigitte ${ }^{\mathrm{a}}$, \\ ${ }^{a}$ CEA, DEN, DTN/SMTA/LIPC Cadarache F-13108 Saint-Paul-lez-Durance, France
}

\begin{abstract}
In sodium fast reactors (SFR), dissolved oxygen in sodium can be monitored via potentiometric sensors with an yttria doped thoria electrolyte. Yttria doped ceria (YDC) was chosen as a simulant material to validate the elaboration process of such sensors. The material must exhibit high density and a fine grain microstructure to be resistant to the corrosion by liquid sodium and thermal shocks. Thus, the oxalic coprecipitation route was chosen to avoid milling steps that could bring impurity incorporation which is suspected to induce grain boundary corrosion in sodium. Powder and sintered pellets were analyzed by BET, XRD and SEM. The results show that synthesis conditions are of first importance on the process yield, the oxalate powder microstructure and, eventually, on the ceramic density and microstructure. The impurity content was limited by controlling the synthesis, calcination and sintering steps. Yttrium content influenced the final microstructure in terms of grain size.
\end{abstract}

Keywords : oxalic precipitation ; oxygen sensors ; SFR ; yttria doped ceria

\section{Introduction}

In sodium cooled fast reactors, the oxygen content in the sodium must be kept under a specific value (usually few ppm), as it controls the corrosion rate of the stainless steel pins [1]. The oxygen monitoring by potentiometric sensors can contribute to this control function. The quality of the electrolyte material is critical to insure the adequate operating of the sensors in the reactor environment[2]. It should be compatible with sodium at high temperature (about $400^{\circ} \mathrm{C}$ ), mechanically resistant and a purely ionic conductor. Actually, no more commercial oxygen sensors for sodium are available.

Yttria doped thoria was commonly used as the electrolyte material in potentiometric sensors for liquid sodium. Thoria is a stable oxide compatible with sodium and the incorporation of yttrium in its lattice produce oxygen vacancies ( $\mathrm{Y}^{\mathrm{III}}$ in a $\mathrm{Th}^{\mathrm{IV}}$ lattice), making the ceramic become an ionic conductor. A highly dense fine grains high purity ceramic is generally required to resist to sodium corrosion and mechanical stress [3]. It was found that oxalic co-precipitation can provide a suitable route for the elaboration of reliable and robust sensors [2]. Thus it was decided by the CEA to develop a similar process to produce such sensors in order to potentially test them in the ASTRID prototype reactor. The process is first developed on a simulant material, in order to gain experience and to qualify the equipment, before working with the radioactive thorium material. This paper deals with the results obtained on yttria doped ceria obtained by oxalic co-precipitation. The final microstructure and the impurity incorporation are discussed as a function of the elaboration conditions.

\section{Experimental part}

\section{1 oxide synthesis, pressing and sintering}

Cerium IV nitrate was used as a precursor in most of the syntheses with the aim of approaching the synthesis conditions with thorium $\left(\mathrm{Th}^{\mathrm{IV}}\right.$ is the only oxidation state for $\mathrm{Th}$, when $\mathrm{Ce}^{\mathrm{III}}$ or $\mathrm{Ce}^{\mathrm{IV}}$ are both possible for cerium). The cerium nitrate $\mathrm{Ce}\left(\mathrm{NO}_{3}\right)_{4}$ is provided as a liquid solution of $1.5 \mathrm{M}$ ionic concentration (Alfa Aesar 13093-17-9, 99.99\%). The cerium III nitrate $\mathrm{Ce}_{2}\left(\mathrm{NO}_{3}\right)_{3}$ used for the last synthesis (L) is in crystal form (Alfa Aesar 11329, 99.5\%) as well as yttrium nitrate $\mathrm{Y}_{2}\left(\mathrm{NO}_{3}\right)_{3}($ Aldrich 13773-79-8, 99.99\%). 
The cationic ratio is $\mathrm{x}=15 \% \mathrm{Y}$ in all casesthe expected final composition is $\mathrm{Ce}_{0,85} \mathrm{Y}_{0,15} \mathrm{O}_{1,925}$ $\left(x=n_{Y} /\left(n_{C e}+n_{Y}\right)=15 \%, n\right.$ number of moles $)$. The nitrates are mixed in water, the cationic concentration of the solution is $1 \mathrm{M}$. The precipitation is obtained by adding oxalic acid, generally slightly in excess of stoichiometric proportion, reaction (1). The concentration of the acid solution is slightly lower than the cationic one, as recommended in [4]. The $\mathrm{pH}$ value can be set at a higher value by adding ammoniac during the precipitation [4]. The mixing of the nitrates in the acid solution can be performed drop by drop from a burette or by a rapid pouring.

$2(1-\mathrm{x}) \mathrm{Ce}\left(\mathrm{NO}_{3}\right)_{4}+2 \mathrm{x} \mathrm{Y}\left(\mathrm{NO}_{3}\right)_{3}+3 \mathrm{H}_{2} \mathrm{C}_{2} \mathrm{O}_{4} \rightarrow \mathrm{Ce}_{2-2 \mathrm{x}} \mathrm{Y}_{2 \mathrm{x}}\left(\mathrm{C}_{2} \mathrm{O}_{4}\right)_{3}+6 \mathrm{H}^{+}+(8-2 \mathrm{x}) \mathrm{NO}_{3}^{-}$

In this oxalate, both cerium and yttrium are at the oxidation state + III, no charge compensation is required. After few minutes of maturation, the oxalate precipitate is separated by ultracentrifugation, rinsed in water until a neutral $\mathrm{pH}$ is obtained, centrifuged, rinsed in ethanol and centrifuged once more. It is dried at $100^{\circ} \mathrm{C}$ during at least 4 hours. The oxalate is gently milled in a mortar (alumina, zirconia and agate were used as the mortar material) and calcined in air between $400^{\circ} \mathrm{C}$ and $700^{\circ} \mathrm{C}$ in alumina crucible, according to reaction (2):

$\mathrm{Ce}_{2-2 \mathrm{x}} \mathrm{Y}_{2 \mathrm{x}}\left(\mathrm{C}_{2} \mathrm{O}_{4}\right)_{3}+(2-\mathrm{x} / 2) \mathrm{O}_{2} \rightarrow 2 \mathrm{Ce}_{1-\mathrm{x}} \mathrm{Y}_{\mathrm{x}} \mathrm{O}_{2-\mathrm{x} / 2}+6 \mathrm{CO}_{2}$

From test I the vessel was systematically cleaned in nitric acid and rinsed in ultrapure water. At each steps, the reactive and products are carefully weighted. Samplings for XRD analysis, SEM observations or thermogravimetric analysis are performed before and after calcination.

The oxide powder is gently milled in mortar and uniaxially pressed (manual hydraulic press SPECAC ${ }^{\mathrm{TM}}$ ) at $300 \mathrm{MPa}$ or $400 \mathrm{MPa}$ in a carbide three-shell mold. Green pellets have a $8-12 \mathrm{~mm}$ large diameter with a height of about $1 \mathrm{~mm}$. The mold surface is lubricated with few zinc stearate before each test.

The pellets are placed in an alumina basket inside a horizontal tubular furnace Nabertherm ${ }^{\mathrm{TM}}$ RHTH 120/300/18. The tube is in C799 alumina. The sintering atmosphere is flowing synthetic air. The synthesis, calcination and sintering conditions are reported in Table 1.

Table 1 : Synthesis conditions, calcination and sintering of the yttrium doped ceria

\begin{tabular}{|c|c|c|c|c|c|c|c|}
\hline Test reference & $\begin{array}{c}\text { Acid } \\
\text { concentration }\end{array}$ & $\begin{array}{c}\text { Rapport. } \\
\text { stœchiométrique } \\
\text { acide/nitrate }\end{array}$ & $\mathrm{pH}$ & Type of pouring & $\begin{array}{l}\text { Oxyde mass } \\
\text { (g) }\end{array}$ & $\begin{array}{l}\text { Temperature/time for } \\
\text { calcination }\end{array}$ & $\begin{array}{l}\text { Sintering } \\
\text { conditions }\end{array}$ \\
\hline A & $0.15 \mathrm{M}$ & $\mathrm{R}=1$ & 6 & Drop by drop & $2 * 3$ & $\begin{array}{l}400^{\circ} \mathrm{C} / 4 \mathrm{~h} \\
700^{\circ} \mathrm{C} / 4 \mathrm{~h}\end{array}$ & $1480^{\circ} \mathrm{C}, 4 \mathrm{~h}$ \\
\hline $\mathrm{C}$ & $0.24 \mathrm{M}$ & $R=3$ & 6 & Drop by drop & $2 * 3$ & $\begin{array}{l}400^{\circ} \mathrm{C} / 4 \mathrm{~h} \\
700^{\circ} \mathrm{C} / 4 \mathrm{~h}\end{array}$ & $1500^{\circ} \mathrm{C}, 4 \mathrm{~h}$ \\
\hline $\mathrm{D}$ & $1 \mathrm{M}$ & $\mathrm{R}=3$ & 6 & Drop by drop & $2 * 3$ & $\begin{array}{l}500^{\circ} \mathrm{C} / 4 \mathrm{~h} \\
700^{\circ} \mathrm{C} / 4 \mathrm{~h}\end{array}$ & $1500^{\circ} \mathrm{C}, 4 \mathrm{~h}$ \\
\hline E_1 & $0.3 \mathrm{M}$ & $\mathrm{R}=1.5$ & 6 & Maturation 1 hour & 1 & & \\
\hline E_2 & $0.3 \mathrm{M}$ & $\mathrm{R}=1.5$ & 6 & Drop by drop & 1 & & \\
\hline E_3 & $0.3 \mathrm{M}$ & $\mathrm{R}=1.5$ & 3 & Drop by drop & 1 & $500^{\circ} \mathrm{C} / 4 \mathrm{~h}$ & $1500^{\circ} \mathrm{C}, 4 \mathrm{~h}$ \\
\hline E_4 & $0.3 \mathrm{M}$ & $\mathrm{R}=1.5$ & 1 & Drop by drop & 1 & $500 \mathrm{C} / 4 \mathrm{n}$ & $1500^{\circ} \mathrm{C}, 4 \mathrm{n}$ \\
\hline E_5 & $0.3 \mathrm{M}$ & $\mathrm{R}=1.5$ & 6 & Direct & 1 & & \\
\hline E_6 & $0.6 \mathrm{M}$ & $\mathrm{R}=3$ & 6 & Drop by drop & 1 & & \\
\hline I & $0.5 \mathrm{M}$ & $\mathrm{R}=1.0$ & 6 & direct & $2 * 15$ & $500^{\circ} \mathrm{C} / 4 \mathrm{~h}$ & $1500^{\circ} \mathrm{C} 2 \mathrm{~h}, 4 \mathrm{~h}$ \\
\hline $\mathrm{J}$ & $0.25 \mathrm{M}$ & $\mathrm{R}=1.0$ & 6 & direct & $3 * 15$ & $500^{\circ} \mathrm{C} / 4 \mathrm{~h}$ & $1500^{\circ} \mathrm{C}, 4 \mathrm{~h}$ \\
\hline $\mathrm{K}$ & $0.2 \mathrm{M}$ & $\mathrm{R}=1.0$ & 5 à 6 & direct & $26 * 6$ & $500^{\circ} \mathrm{C} / 4 \mathrm{~h}$ & $1500^{\circ} \mathrm{C}, 4 \mathrm{~h}$ \\
\hline $\mathrm{L}$ & $0.2 \mathrm{M}$ & $\mathrm{R}=1.0$ & 5 à 6 & direct & $30 * 12$ & $500^{\circ} \mathrm{C} / 4 \mathrm{~h}$ & $\begin{array}{c}1500^{\circ} \mathrm{C} \\
1 \mathrm{~h}, 2 \mathrm{~h}, 4 \mathrm{~h}, 8 \mathrm{~h}\end{array}$ \\
\hline
\end{tabular}

2.2 Characterization

Direct observations of the surface of the pellets were usually performed, but some of them were also polished in order to observe the bulk microstructure. In the latter case, a thermal etching $\left(1200^{\circ} \mathrm{C} 2 \mathrm{~h}\right)$ is necessary to reveal the microstructure. The metallographic examinations were performed in a $\mathrm{LaB}_{6}$ $\mathrm{ZEISS}^{\mathrm{TM}} \mathrm{EVO}^{\circ} \mathrm{HD} 15 \mathrm{MA}$ with backscattered electrons. It is equipped with a SDD SX50 energy dispersive spectrometer for chemical analysis. Image analyses were performed with the AnalySIS ${ }^{\mathrm{TM}}$ software. 
XRD was performed in the $\theta-\theta$ mode with a BRUKER ${ }^{\mathrm{TM}}$ D5000 diffractometer, BET with a Quantachrome Autosorb-1, using nitrogen as absorbed gas. The thermogravimetric analyses are carried out with a horizontal furnace Mettler Toledo ${ }^{\mathrm{TM}}$ TGA/SDTA851e thermobalance, gas analysis is performed with a micro chromatograph Agilent ${ }^{\mathrm{TM}}$ 2891a. Density determination was carried out with a Mettler-Toledo MS14S ( $\pm 0,05 \mathrm{mg}$ ) equipped with a volumetric mass determination kit MS DNY-43, from a weighting in air (pellets dried at $100^{\circ} \mathrm{C}$ ) and a weighting in pure ethanol. The accuracy (from measurement scattering) is $\pm 0.04 \mathrm{~g} . \mathrm{cm}^{-3}$. It was found that pure ethanol satisfactorily penetrates in the ceria porosity. An incomplete penetration would induce an under-estimation of the density (as a part of the open porosity would be accounted as close porosity). As the open porosity is not taken into account in this method, it might lead to an over-estimation of the real density: the relevance of the density determination is then confirmed by the microscopic observation of the surface.

\section{Results}

\subsection{Synthesis yield}

The synthesis yield is obtained by the ratio of the cations in oxide form over the cations in the nitrate solution. The calculated values are reported in Table 2.

The oxalate precipitation was observed immediately after the pouring of the nitrate in the oxalic acid (reaction 2). The maturation time is usually of a few minutes, but for test with incomplete reaction, oxalate precipitation could be observed in the rinsing water several hours after the test (yellow coloration). Complete yields were obtained only when direct pouring was used, but it is not a sufficient condition. Also, it is necessary that the oxalic solution is diluted enough in order to avoid the temperature increase of the solution due to the exothermicity of the reaction (tests $\mathrm{H}$, I and J). It should be noted that complete yield can be obtained even if the oxalic acid is slightly over stoichiometric (reaction 1).

Yields above $100 \%$ were obtained for batch of high quantity of powder (synthesis K 150g), which for an accurate monitoring was not required. When accurate monitored, the yields are rather close to $100 \%$ (rather 102\%). A yield above $100 \%$ cannot be explained by the presence of impurities ( $\mathrm{Si}, \mathrm{Al}$ ) as the last pellets contained few of them. It is rather attributed to water or $\mathrm{CO}_{2}$ absorption. In fact two mass losses of about $1 \%$ are observed in TGA measurements for the oxide powder: one between $70^{\circ} \mathrm{C}$ and $120^{\circ} \mathrm{C}$, one between $150^{\circ} \mathrm{C}$ and $700^{\circ} \mathrm{C}$ (the latter being rather linear with time). Each time, $\mathrm{CO}_{2}$ release is observed, but it accounts for less than about $10 \%$ of the total mass loss between $70^{\circ} \mathrm{C}$ and $120^{\circ} \mathrm{C}$ and $30 \%$ of the total mass loss between $150^{\circ} \mathrm{C}$ and $700^{\circ} \mathrm{C}$. Rather similar results are obtained under air and under $\mathrm{Ar} / \mathrm{H}_{2}$ $3 \%$ (slightly higher mass loss under reducing atmosphere). Under air, few hydrogen is also released between $170^{\circ} \mathrm{C}$ and $370^{\circ} \mathrm{C}$. After sintering, the total mass loss is about $4 \%$.

The synthesis with the cerium III nitrate is much easier. The $\mathrm{pH}$ is easier to adjust, the precipitation is instantaneous and the oxalate exhibits a white color (found only for the syntheses at $\mathrm{pH}=1$ with $\mathrm{Ce}^{\mathrm{IV}}$ nitrate). The yellow color of the oxalate obtained with $\mathrm{Ce}^{\mathrm{IV}}$ at $\mathrm{pH}=6$ could be induced by impurity coprecipitation.

\subsection{Powder microstructure}

For the oxalate, the hydration number per cerium unit at any $\mathrm{pH}$ was calculated to be between 1.5 and 5 from the weight measurements. The XRD peaks can correspond to the cerium oxalate hydrated 5 times (per cerium unit) but for some syntheses, the compounds could not be identified. It is likely that the oxalate can be dehydrated during the more or less long drying time at $100^{\circ} \mathrm{C}$. No yttrium oxalate peaks were detected; it is then concluded that the co-precipitation leads to the formation of a mixed oxalate.

As only one Fm3m cubic phase is observed by XRD for the oxide powder, it can be concluded that an yttrium cerium mixed oxide is formed. The oxide crystallite size was estimated from the width of the peaks, using the Debye-Scherrer formula. It varies from $\approx 10 \mathrm{~nm}(6-11 \mathrm{~nm})$ for a calcination temperature of $400^{\circ} \mathrm{C}$ or $500^{\circ} \mathrm{C}$, to $\approx 30 \mathrm{~nm}(26-32 \mathrm{~nm})$ for a calcination temperature of $700^{\circ} \mathrm{C}$.

Some micrographies of the oxide powders are reported in Figure 1. Obviously, the powder is constituted by grains forming plates or parallelepipeds (not rectangular) of few micron size (so containing several 
crystallites) which are more or less agglomerated (the biggest agglomerates have a often common centre). The smallest grains, forming few agglomerates, were obtained for the syntheses performed at high $\mathrm{pH}$ (3 or 6) and rapid pouring (test E5, F1, G...). However, such microstructure was not obtained when the mixture was inadequate or when the temperature in the reactor rose, leading to bigger size grains and agglomeration (tests $\mathrm{H}$ and I). The grains size varies from 1 to $10 \mu \mathrm{m}$.

It should be noted that oxide and oxalate powder grains are isomorphic. The calcination does not lead to the morphologic transformation of the powder.
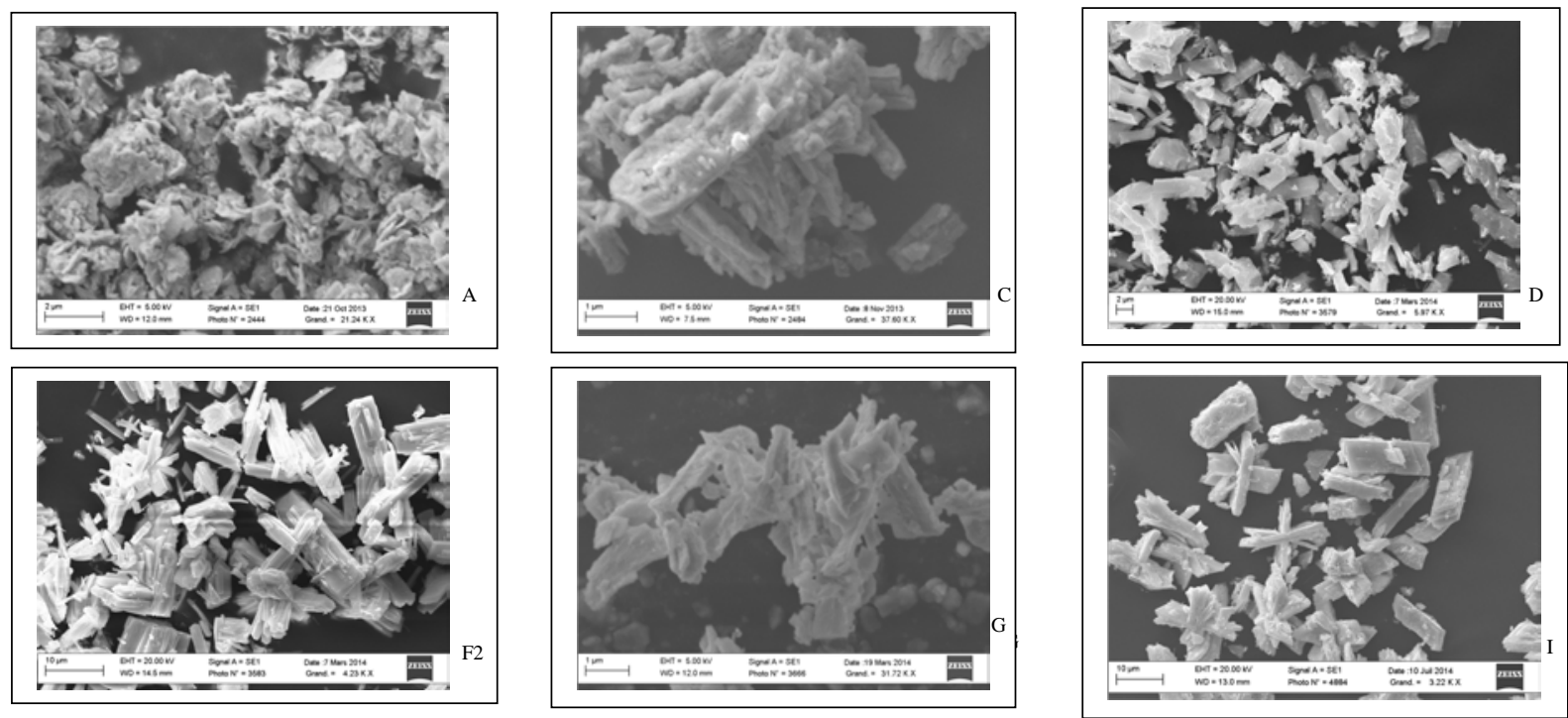

Figure 1 : SEM micrographies of the oxide powder in different synthesis conditions

The BET specific surface of the oxalates is lower than $10 \mathrm{~m}^{2} \cdot \mathrm{g}^{-1}$, when it is larger than $20 \mathrm{~m}^{2} \cdot \mathrm{g}^{-1}$, up to 85 $\mathrm{m}^{2} \cdot \mathrm{g}^{-1}$, for the oxides. As the powder morphology is unchanged, it could be considered that the ratio of the specific surfaces should vary as $\left(\rho_{\mathrm{Y}}{ }^{2 / 3} \cdot \mathrm{M}_{\mathrm{Y}}{ }^{1 / 3}\right) /\left(\rho_{\mathrm{A}}{ }^{2 / 3} \cdot \mathrm{M}_{\mathrm{A}}{ }^{1 / 3}\right)$, where $\mathrm{M}$ holds for the molar mass and $\rho$ for the density of the oxalate A oxide Y respectively. According to this assumption the ratio of the specific surface of the oxalate over the oxide one should be 1.66, when it is lower than 0.5 .

In fact, the calcination leads to the formation of a large porosity inside the grains, without changing their morphology. This surface specific increase is interpreted as the creation of a large mesoporosity induced by the release of the gaseous molecules $\left(\mathrm{CO}_{2}, \mathrm{CO}\right)$ during the calcination [5].

For two powders calcined and synthesized in similar condition, excepted $\mathrm{pH}$, the powder synthesis at $\mathrm{pH}=1$ exhibits a bigger grains size and a lower specific surface $\left(57 \mathrm{~m}^{2} \cdot \mathrm{g}^{-1}\right)$ than the one at $\mathrm{pH}=3$ with a smaller grains size and a bigger specific surface $\left(77 \mathrm{~m}^{2} \cdot \mathrm{g}^{-1}\right)$. The specific surface decreases as the calcination temperature is increased $\left(22\right.$ and $85 \mathrm{~m}^{2} \cdot \mathrm{g}^{-1}$ for the test powder $\mathrm{C}$ calcined at $400^{\circ} \mathrm{C}$ and $700^{\circ} \mathrm{C}$ respectively). This can be interpreted as following: the large mesoporosity created by the rapid release of the gas at $400-500^{\circ} \mathrm{C}$ gets progressively close or eliminated as the crystallite size increases at $700^{\circ} \mathrm{C}$ (intergranular sintering).

\subsection{Pellet microstructure}

The highest pellets densities were obtained only with powder with a grain size lower than $2 \mu \mathrm{m}$ (see Table 2). For the dense pellets, the porosity is generally intergranular (see Figure 2). Some pellets were thought to be dense after the volumetric mass determination by double weighting, but it appears that a large interconnected open porosity can exist (tests E3, H, J).

The average grain size varies is between 1 and $2 \mu \mathrm{m}$. It is smaller than the powder grain size, which proves that they are constituted of crystallites of smaller size. It was not possible to find a relation between the calcination temperature and the pellet grain size.

The yttrium over cations $(x)$ ratio was checked by EDS. For $x=15 \%$, the results are systematically higher in the EDS analyses: between 1 and 30\%, but especially on non-polished surface. On polished surface, the difference is less than $10 \%$ for $x=15 \%$. Then, EDS is not really adequate to check the scattering in yttrium concentration. The tentative to analyze the XRD peaks was not successful. A slight deviation of the cell 
parameter was observed, but its decrease is much lower than the reported values in the literature [6] $(\mathrm{a}=0,5410 \mathrm{~nm}$ for $\mathrm{x}=15 \%$ to be comparted to $0.5406 \mathrm{~nm}$ as proposed by Bryan Balazs et al., $0.5412 \mathrm{~nm}$ for $\mathrm{x}=0 \%)$.

Table 2 : test results : doping ratio $x$, reaction yield, oxide density, pellet grain size and pollutants

\begin{tabular}{|c|c|c|c|c|c|c|}
\hline $\begin{array}{c}\text { Teste } \\
\text { reference }\end{array}$ & $\begin{array}{l}\text { final } x \\
(\%)\end{array}$ & Yield (\%) & Density $\left(\mathrm{g} \cdot \mathrm{cm}^{-3}\right)$ & $\begin{array}{l}\text { Density (\%vs } \\
\text { theoritical) }\end{array}$ & $\begin{array}{c}\text { Grain sise } \\
(\mu \mathrm{m})\end{array}$ & Impurity in pellets \\
\hline A & 14.0 & 70 & $<5.9$ & & & $\begin{array}{c}\mathrm{Si}>\mathrm{Ca}>>\mathrm{Al} \\
\text { Rods }\end{array}$ \\
\hline $\mathrm{C}$ & 14.8 & 69 & $6.2-6.5$ & $90-95$ & $1 . .7 \pm 0 . .7$ & $\mathrm{P}$ \\
\hline D & 14.9 & 76 & $6.1-6.4$ & $89-93$ & $0.8-1.8$ & No \\
\hline E_1 & 15.0 & 76.4 & 6.4 & 93 & & \\
\hline E_2 & 15.0 & 80.3 & 5.7 & & & E_2: Si>Ca>>Al \\
\hline E_3 & 15.0 & 74.1 & $6.7 ?$ & 97.5 & & Rodes $+\mathrm{Al}_{2} \mathrm{O}_{3}$ grains \\
\hline E_4 & 15.0 & 88.2 & 6.7 (open) & $?$ & & \\
\hline E_5 & 15.0 & 100.2 & 6.6 & 96 & E_5 : $2 \pm 1$ & $\mathrm{E} \_5: \mathrm{Al}_{2} \mathrm{O}_{3}$ grains \\
\hline E_6 & 14.9 & 56.6 & 5.9 & 86 & & \\
\hline $\mathrm{F}$ & 14.9 & $\begin{array}{l}98.5 \\
93.1\end{array}$ & $\begin{array}{c}6.8 \text { (open.) } \\
6.3 \text { (open++) }\end{array}$ & $\begin{array}{c}? \\
<92\end{array}$ & & No \\
\hline G & 15.1 & 96.1 & $6.77 \pm 0.02$ & 98.6 & $\begin{array}{c}\text { bulk } 1 \pm 0.4 \\
\text { surface } 1.4 \pm 0.4\end{array}$ & $\begin{array}{c}\text { bulk } \mathrm{Si}>\mathrm{Ca}>>\mathrm{Al} \\
\text { rods }+\underset{\text { grains in } \& \text { around }}{\text { porosity }}\end{array}$ \\
\hline $\mathrm{H}$ & 15.1 & $\begin{array}{c}100 \\
66 \\
70\end{array}$ & $\begin{array}{c}6.77 \pm 0.02 \\
6.5(\text { open }++)\end{array}$ & 98.6 & $1.3 \pm 0.4$ & P Plates \\
\hline I & 15.0 & $72-100$ & 6.6 & 96 & & $\begin{array}{c}\text { P. Si. Ca } \\
\text { Dendrites around porosity } \\
\text { P Plates }\end{array}$ \\
\hline $\mathrm{J}$ & 15.0 & $82-101$ & 6.3-6.6 (open++) & $92-96$ & & oui \\
\hline K & $14.7-15.3$ & $98-106$ & 6.7 & 97.5 & $1.8 \pm 0.7$ & $\mathrm{P} ; \mathrm{Al}_{2} \mathrm{O}_{3}$ grains \\
\hline $\mathrm{L}$ & 15.0 & $97-110$ & $\begin{array}{l}6.76 \pm 0.02 \\
6.75 \pm 0.02 \\
6.75 \pm 0.01 \\
6.76 \pm 0.02\end{array}$ & $98.4-99.2$ & $\begin{array}{c}0.6-0.75 \pm 0.25 \\
0.9-1.0 \pm 0.4 \\
1-1.3 \pm 0.4 \\
1.5-1.65 \pm 0.4\end{array}$ & $\begin{array}{l}\text { Si. Ca. Al in bulk around } \\
\text { porosity }\end{array}$ \\
\hline
\end{tabular}

\subsection{Pollution}

The main impurities observed on or in the pellets are reported in Table 2. This is illustrated in Figure 2, with micrographies of the most frequent type of pollutions.

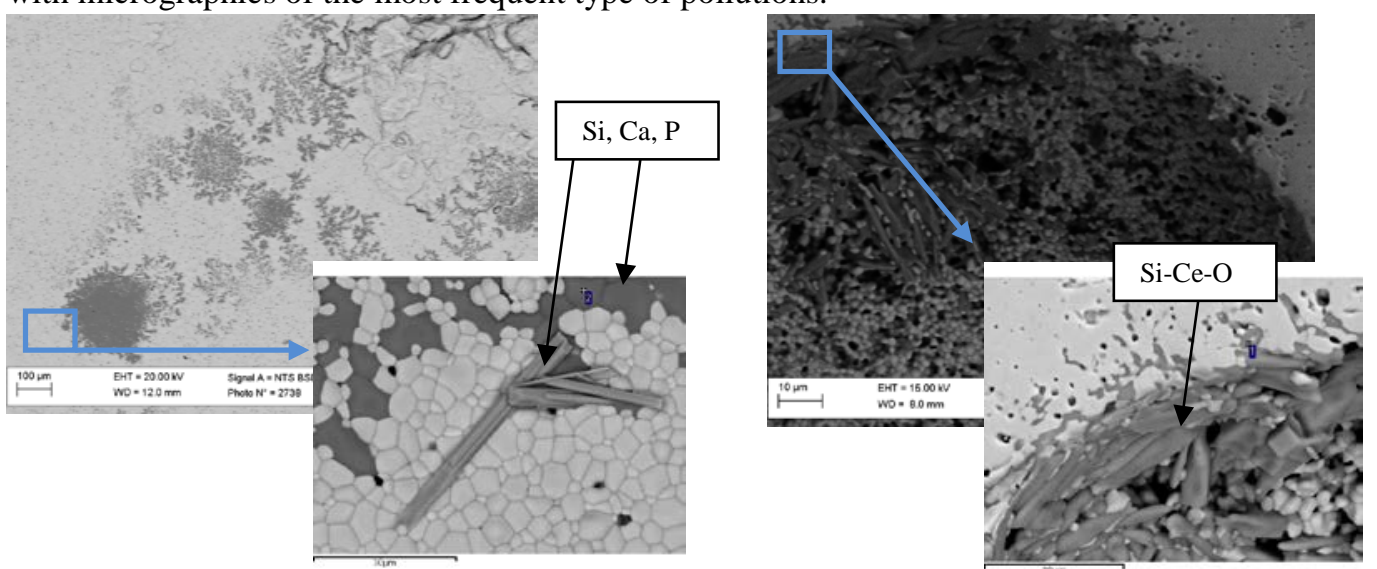

Figure 2 : Typical impurities observed on (left test $C$ ) and in (right test $G$ ) the pellets.

In the first tests, many pollutants are observed on the surface, forming rods (50 $\mu \mathrm{m}$ long, $2 \mu \mathrm{m}$ wide) or dendrites made of grains. They are composed of silicon and calcium oxide mixed with yttrium, aluminum and cerium. In some cases, phosphorus was also observed, and in some tests, alone in plates (sometimes in large quantities, in some particular locations at the surface).

After the test $\mathrm{F}$ aluminum, which was until then hardly observed, becomes one of the main detected impurity. Si and Ca are sometimes observed, but in lower quantity than in the previous syntheses. As the china mortar was replaced by an agate one and then by a zirconia or a pure alumina mortar, the milling could be one of the main causes of the large pollutions observed in the first tests. 
No impurity could be detected in the powders by SEM, but the detection of impurity is not easy when very small grains are observed.

Sample G was cross section polished and observed by SEM. Some few large spherical or ellipsoidal pores (size between 10 and $100 \mu \mathrm{m}$ ) are observed with impurities at their edges and bottom (Figure 2). Impurity grains are oxides rich in aluminum (with yttrium) or in silicon (with cerium and few calcium). In one case, some $\mathrm{SiO}_{2}$ was observed inside the porosity. It reacts during the sintering and formed a mixed cerium silicon oxide at the interface. This compound is also visible around the porosity. For the test $\mathrm{G}$, the powder was milled in an agate $\left(\mathrm{SiO}_{2}\right)$ mortar.

However, silicon and calcium incorporations, as well as few phosphorus and aluminum are sometimes found in the next tests though: the powder was milled in a zirconia mortar, the vessel was systematically rinsed in nitric acid, ultrapure water was used and the alumina furnace tube was heated under vacuum at $1700^{\circ} \mathrm{C}$ (to volatilize residual impurities).

For the test $\mathrm{L}$, the only observed impurities $\left(\mathrm{SiO}_{2}, \mathrm{P}\right)$ could be attributed, according to their size and location, to residual contamination on the pressing heads of the pressing machine (due to their polishing). But impurities were also found in the bulk by polished cross section, always at the vicinity of large spherical/ellipsoidal porosities. These impurities formed rods and grains containing $\mathrm{Si}$, Ca and $\mathrm{Al}$ (with Y in the rods and Ce in the grains). The crystal growth appears to be oriented, and the apparition of the particular porosity could be related to these pollutants.

An ultrapure Ce $\mathrm{CIII}^{\mathrm{III}}$ nitrate was used for the first of the 30 syntheses of test conditions L. In that case, the oxalate is easier to mill, white color, as well as the oxide pellets after sintering. A lower quality cerium was used for the second part of the syntheses: the oxalate is still white but the pellets are orange color after sintering.

Thus it is likely that there are many origins for the impurities: the systematic washing up of the vessel with nitric acid, rinsing with ultrapure water, milling with mortars more resistant to abrasion clearly improve the purity of the pellets. However, it is likely that the main origin of the impurity (at least Si and $\mathrm{Ca}$ ) is the aqueous synthesis, at the higher $\mathrm{pH}$, especially when $\mathrm{Ce}^{\mathrm{IV}}$ nitrate is used. In such conditions, it is likely that the impurities come from the reactants or from the vessel and co-precipitate with the mixed yttrium cerium oxide. More specifically, the phosphorus could come from the yttrium nitrate, as the yttrium is extracted from phosphorus based compounds (monazite).

\subsection{Discussion}

These results show that the aqueous synthesis must be tightly controlled in order to obtain the target microstructure. A small aggregates powder (about one micron) is necessary to obtain a highly dense ceramic. The elaboration of large quantities of a high quality powder is limited in a simple reactor by the control of the synthesis conditions, $\mathrm{pH}$ and temperature (for example in test $\mathrm{H}$ conditions, three syntheses, three different yields).

In order to obtain small size aggregates, the nucleation of the oxalate particles must be favored at the expense of their growth. The direct pouring of the cationic solution favors the cation supersaturation in acid and then decreases the size of the critical nucleus. In the classical theory of nucleation, the size of the critical nucleus determines the rate of nucleation, proportional to $\sigma / k$.T.lnS, with $\sigma$ the surface energy of the nucleus, $\mathrm{k}$ the Boltzmann's constant, $\mathrm{T}$ the temperature (in Kelvin) and $\mathrm{S}$ the supersaturation defined as the concentration in the solution over the equilibrium concentration.

An increase of the acid quantity ( $\mathrm{R}$ in Table 1 ) or of its concentration do not allow the increase of the supersaturation. In fact the temperature plays a more important role than supersaturation in the nucleation rate. The quantity of reactants must be limited and the oxalic acid be diluted enough (at about $0.2 \mathrm{M}$ ) to avoid a temperature increase due to the reaction exothermicity (at least in basic reactors).

At the contrary, a high $\mathrm{pH}$ allow the dissociation reactions of $\mathrm{H}_{2} \mathrm{C}_{2} \mathrm{O}_{4}\left(\mathrm{pK}_{\mathrm{A} 1}=1.2, \mathrm{pK}_{\mathrm{A} 2}=4.3\right)$ without being limited by the formation of a strong acid $\left(\mathrm{HNO}_{3}\right.$, displacement of reaction 2 to the right side). From $\mathrm{pK}_{\mathrm{A}}$ it can be calculated that at a $\mathrm{pH}=1$, the ratio $\left[\mathrm{C}_{2} \mathrm{O}_{4}{ }^{2-}\right] /\left[\mathrm{H}_{2} \mathrm{C}_{2} \mathrm{O}_{4}\right]$ is $10^{-3,5}$, when it is $10^{6,5} \mathrm{at} \mathrm{pH}=6$. 
The precipitation is easier from a $\mathrm{Ce}^{\mathrm{III}}$ nitrate to form a $\mathrm{Ce}^{\mathrm{III}}$ oxalate. It can be expected that similarly large quantity of $\mathrm{Th}^{\mathrm{IV}}$ oxalate could be rather easily obtained from a $\mathrm{Th}^{\mathrm{IV}}$ nitrate following the conclusions drawn from our experience with cerium (rapid pouring, control of the reaction conditions...). However, the co-precipitation of an oxalate mixture of cation at the oxidation IV (Th) and III (Y) will require charge compensation (necessity of $\mathrm{H}_{3} \mathrm{O}^{+}$integration). Thus, a high $\mathrm{pH}$ synthesis could be less favorable for the thorium oxalate nucleation, as the displacement of the reaction towards the oxalic acid decomposition at high $\mathrm{pH}$ could be balanced by the necessity to keep a high proton concentration enough to compensate the charge of the oxalate. The $\mathrm{pH}$ value selected in most of our syntheses $(\mathrm{pH}=6)$ allows us to obtain the desired yield and microstructure, but it is also likely that it also induces the co-precipitation of impurities.

The formation of a liquid phase during sintering by the impurities (e.g. $\left.\mathrm{CaO}-\mathrm{SiO}_{2}\right)$ or with $\mathrm{Y}(\mathrm{Al}, \mathrm{Si})$ or $\mathrm{Ce}(\mathrm{Si})$ could lead to their diffusion from the bulk towards the surface by capillarity; these surfaces could also be the edges of the large bulk porosities. Then, they would crystallize as rods, dendrites, etc, during the cooling. The particular reactivity of the impurities during the sintering should be investigated.

\section{Conclusion}

The test allows us to define the process conditions to obtain the mixed yttrium cerium oxide with the microstructure that was aimed at: dense with fine grains. The main parameters to be controlled are the mixing rate, the $\mathrm{pH}$ and the synthesis temperature.

These tests allow us also to estimate the volume of effluents that will be produced, as it is important to properly manage the radioactive (thorium) wastes. In effect, it is necessary to have an oxalic acid diluted enough in order to obtain an almost complete yield.

The parameters concerning the calcination, pressing and sintering appeared to be less important. Calcination at $500^{\circ} \mathrm{C}$ produces an oxide powder with nanocrystallites $(\approx 10 \mathrm{~nm})$ and a high specific area. It is not clear whether carbon is incorporated in large amounts or not in the powder, and the influence of the calcination temperature on it should be investigated.

It was highlighted by these tests that many sources of impurities can pollute the pellets. Impurities at the grain boundary might be responsible for sodium local attack of the ceramic. Considering this, the choice of a co-precipitation process that limit an energetic milling step, which might induce large pollutions seems particularly relevant.

\section{References}

1. Brissonneau, L., New considerations on the kinetics of mass transfer in sodium fast reactors: An attempt to consider irradiation effects and low temperature corrosion. Journal of Nuclear Materials, 2012. 423(1-3): p. 67-78.

2. Thompson, R., et al. Experience of the production, performance and application of harwell oxygen meter tubes. in LIMET Liquid Metal Technology. 1980. Richland, USA.

3. Ganesan, R., et al., Novel approach for the bulk synthesis of nanocrystalline yttria doped thoria powders via polymeric precursor routes. Journal of Nuclear Materials, 2004. 325(2-3): p. 134140.

4. Van Herle, J., et al., Oxalate coprecipitation of doped ceria powder for tape casting. Ceramics International, 1998. 24(3): p. 229-241.

5. Hingant, N., et al., Preparation, sintering and leaching of optimized uranium thorium dioxides. Journal of Nuclear Materials, 2009. 385(2): p. 400-406.

6. $\quad$ Bryan Balazs, G. and R.S. Glass, ac impedance studies of rare earth oxide doped ceria. Solid State Ionics, 1995. 76(12): p. 155-162. 